\title{
Pricing Based on the Binary Tree Model Under Public Infrastructure Projects
}

\author{
Dongjun Fan \\ Business colleuage \\ Hohai University \\ Nanjing, 210000, China \\ E-mail: ddyjgl10701@163.com
}

\begin{abstract}
Purpose] In order to address the problem of pricing public infrastructure project based on the binary tree model. [Method] By the real option binary tree model. [Conclusions] This article makes a pricing research on public infrastructure projects to. At the same time, this article makes policy recommendations for the investment powers and the government respectively.
\end{abstract}

Keywords- public infrastructure; project pricing; real options; binary tree model

\section{INTRODUCTION}

With the rapid economic development, public infrastructure has increasingly strong demand, and the trend for large scale investment projects is becoming increasingly apparent. Public infrastructure is a kind of public good that provides services for the whole community. And it is also an indispensable hardware in the process of economic development. Only government financial expenditure can not solve the fundamental problem of the construction of public infrastructure.

Public infrastructure investments have a long construction period, high-risk and a huge capital demand. Its value is precisely decided by this uncertainty. Investor can determine the value of the development project again with continuous-obtained information after the start of the project. As a basis to make the decision to continue to invest or abandon investment, investor can get effective risk aversion. The net present value as the main representative of the project investment decisions largely ignored the opportunity cost of the investment flexibility and investment decisions have been unable to adapt to the needs of the current investment.

\section{The APPLICATION OF BINARY TREE OPTION PRICING MODEL}

\section{A. Determination of the variable}

(1) The current value of the assets of the investment in infrastructure projects $\left(S_{0}\right)$. That the execution of the option prices

(2) Option exercise price(X). The option exercise price of the investment in infrastructure projects generally is the sum of the current cost of the investment in the project life cycle.

(3) Interval of each of options ( $t$ ).
(4) The options useful life of the infrastructure projects (T). The life of the general project options is 3-6 months. But due to some external factors in the real world, options need time long enough to eliminate the uncertainty. As a result we delay the options life of the project to 15 months.

(5) Volatility of the value of the investment in infrastructure projects $(\sigma)$. The variable measures the variability of the total value of its assets related projects in the life of its option. Calculating volatility already reached a consensus approach to decision making. The volatility is calculated through management optimistic estimate $\left(S_{\text {opt }}\right)$ and pessimistic estimate $\left(S_{\text {pes }}\right)$ of the expected return, and the given life cycle of the project $(\mathrm{T})$, the formula is:

$$
\sigma=\ln \frac{S_{o p t} / S_{p e s}}{4 \sqrt{T}}
$$

(6) The necessary yield or the risk-free rate of return of all necessary infrastructure projects owners yield or risk-free rate of return is $r$.

(7) The value of the infrastructure projects may raise $u$ or may drop $\mathrm{d}$. In the binary tree option pricing model, the underlying value is the expectation resulting from risk neutral probability $\mathrm{p}$ in the high state and low state of the future. Then the discounted present value discounted at the risk-free rate $r$.

At the end of the period $\mathrm{T}$, the expectation of the pricechanging rate of the infrastructure projects is:

$$
p(u-1)+(1-p)(d-1)=e^{r t}-1
$$

We can get the price-changing rate of the value of the underlying assets in a period:

$$
\begin{aligned}
& p=\frac{e^{r t}-d}{u-d} \\
& \text { And } u=e^{\sigma \sqrt{t}}, \quad d=\frac{1}{u}=e^{-\sigma \sqrt{t}}
\end{aligned}
$$

(8) The infrastructure project value at the end of each period is $\delta$ times over the value at the time. (We assume that all the owners of infrastructure projects are rational).

Using risk-neutral pricing method, the binary tree of the value of the infrastructure projects is as shown on figure 1 .. 


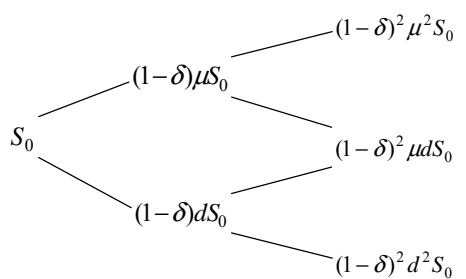

Figure 1. The binary tree of the value of the infrastructure projects

\section{B. The calculation of the options value}

The options value on each node in the binary tree can be calculated by backward induction method. And decisionmaking rules apply to each node, starting from the right side of the binary tree, choose the best decision. Calculating the waiting option value $(1-\delta)^{2} u^{2} S_{0}$ needs to be carried out in accordance with the following steps:

Step

$(1-\delta)^{2} u^{2} S_{0}=\left\{p\left[(1-\delta)^{3} u^{3} S_{0}\right]+(1-p)\left[(1-\delta)^{3} u^{2} d S_{0}\right]\right\} e^{-r \Delta t}$

Step 2: $(1-\delta)^{2} u^{2} S_{0}=\max \left((1-\delta)^{2} u^{2} S_{0}-X, 0\right)$, For the call options; option.

$$
(1-\delta)^{2} u^{2} S_{0}=\max \left(X-(1-\delta)^{2} u^{2} S_{0}, 0\right), \text { For the put }
$$

Select the highest value between step 1 and step 2, and identify the option value. The same process is repeated until we start to get the project's equity price $\left(S_{0}\right)$.

Assuming that an infrastructure projects option that will expire after $\mathrm{T}$ years can be purchased.

First, the analysis of the call option value:

(1)When $(1-\delta) u<1$, Call option is worthless

(2)When $(1-\delta) u \geq 1$, Call option is valuable only in the case that the value of two infrastructure projects is up. And there are two cases:

$$
\text { First, when } \frac{\left[(1-\delta)^{2} u^{2}-1\right] p}{(1-\delta) u-1} \geq e^{T}
$$
call option will wait for the options to expire and choose whether to perform instead of exercising the option in advance. The value of the options at this time is $\left[(1-\delta)^{2} u^{2}-1\right] e^{-2 T} p^{2} S_{0}$.

Second, when $\frac{\left[(1-\delta)^{2} u^{2}-1\right] p}{(1-\delta) u-1}<e^{T}$ , the power method of call option will choose to exercise the option in advance. The value of the options at this time is $[(1-\delta) u-1] e^{-T} p S_{0}$

At the same time, the analysis of the value of the put option:

(1)When $(1-\delta) u \geq 1$, Put option is worthless only in the case that the value of two infrastructure projects is up. And there are two cases:
First, when $\frac{\delta^{2} p+\left[1-\left(1-\delta^{2}\right) d^{2}\right](1-p)}{1-(1-\delta) d} \geq e^{T}$, The power method of put option will wait for the options to expire and choose whether to perform instead of exercising the option in advance. The value of the options at this time is $\left\{2 \delta^{2} p(1-p)+\left[1-\left(1-\delta^{2}\right) d^{2}\right]\left(1-p^{2}\right)\right\} e^{-2 T} S_{0}$

Second, when $\frac{\delta^{2} p+\left[1-\left(1-\delta^{2}\right) d^{2}\right](1-p)}{1-(1-\delta) d}<e^{T}$, in the case of a decline in the infrastructure projects value in the first phase, the power method of put option will choose to exercise the option in advance. The value of the options at this time is $\left\{[1-(1-\delta) d] e^{-T}(1-p)+\delta^{2} p(1-p) e^{-2 T}\right\} S_{0}$

(2)When $(1-\delta) u<1$, regardless of how changes in the value of the two infrastructure projects, put option has the value. And there are three cases:

$$
\text { First, when } \frac{\delta^{2} p+\left[1-\left(1-\delta^{2}\right) d^{2}\right](1-p)}{1-(1-\delta) d} \geq e^{T}
$$

, The power method of put option will wait for the options to expire and choose whether to perform instead of exercising the option in advance. The value of the options at this time is $\left\{2 \delta^{2} p(1-p)+\left[1-\left(1-\delta^{2}\right) d^{2}\right](1-p)^{2}+\left[1-\left(1-\delta^{2}\right) u^{2}\right] p^{2}\right\} e^{-2 T} S_{0}$;

Second,

when

$$
\frac{\delta^{2} p+\left[1-\left(1-\delta^{2}\right) d^{2}\right](1-p)}{1-(1-\delta) d}<e^{T}
$$
and

$$
\frac{\delta^{2}(1-p)+\left[1-\left(1-\delta^{2}\right) u^{2}\right] p}{1-(1-\delta) u} \geq e^{T}
$$
, in the case of a decline in the infrastructure projects value in the first phase, the power method of put option will choose to exercise the option in advance. The value of the options at this time is $[1-(1-\delta) d] e^{-T}(1-p) S_{0}+\left\{\delta^{2} p(1-p) e^{-2 T}+\left[1-\left(1-\delta^{2}\right) u^{2}\right] p^{2}\right\} e^{-2 T} S_{0}$;

$$
\text { Third, when } \frac{\delta^{2}(1-p)+\left[1-\left(1-\delta^{2}\right) u^{2}\right] p}{1-(1-\delta) u}<e^{T}
$$
, the power method of put option will choose to exercise the option in advance, regardless of the value of the infrastructure projects in the first phase up or down. The value of the options at this time is: $\{[1-(1-\delta) d](1-p)+[1-(1-\delta) u] p\} e^{-T} S_{0}$.

\section{The POLICY RECOMMENDATIONS}

\section{A. The powers side investment recommendations}

(1)When infrastructure investment powers use valuation binary tree model of the real options to price, first of all they need to make a judgment of their own decision-making and its development process to determine its compliance with the process structure of the binary tree model.

(2)The powers of the infrastructure investment side need to make predictions in response to market demand trends. 
(3) In order to calculate the real options value of infrastructure projects, infrastructure investment powers need to estimate future earnings as accurate as possible.

(4) For the powers of the infrastructure investment, there will be a bottom line of an acceptable rate of return on investment in accordance with the risk-free rate of return (r) in the real options binary tree pricing model.

\section{B. Government's policy recommendations}

(1) Reasonable control of the structure of the urban infrastructure investment.

(2) Adjust the space layout and construction sequence of city infrastructure investment.

(3) Make a stage grasp of the city infrastructure investment.

(4) Make a recognition for the effect of different types of city infrastructure investment.

(5) Reasonable control of the scale of investment.

\section{REFERENCES}

[1] John $\cdot$ Hull. Options, futures and other derivatives. Huaxia press, 1997.

[2] Chunpeng Yang. Real options and its application. Fudan University press, 2003, 25-53.

[3] Weihua Zeng. The real option method in investment decision of real estate development application. Wuhan university, 2004.

[4] Yongfeng Zhang, Hanlin Chen. Oil and gas exploration and development project real option model research. Natural gas industry, 2006, (2) , 138-141.

[5] Han T J Smit. Infrastructure Investment as a Real Options Game : the Case of European Airport Expansion. Financial Management, 2003, (2) : 5-35

[6] Han T J Smit, Lenos Trigeorgis. Strategic Investment: : Real Options and Games. Princeton University Press, 2004 : 72-118.

[7] Guohua Li, Kai Li. The application of real option' s the binary tree model.: investment under uncertain environment. Journal of Jiangxi Finance and Economics University, 2002, (3) : 50-53. 